SEMBLANZA

Rev Chil Salud Pública 2019, Vol 23(2): 172-173

\title{
SEMBLANZA DOCTORA PATRICIA FRENZ
}

\author{
IN MEMORIAM: DR. PATRICIA FRENZ
}

Rigurosa, comprometida y aguda, la Dra. Patricia Frenz representa una potente figura para la Escuela de Salud Pública de la Universidad de Chile y deja una huella imborrable, por su incansable trabajo en torno a la superación de las desigualdades en salud.

Médico Cirujano de la Universidad de Chile, Doctora en Salud Pública y abogada de la New York University de Estados Unidos, marcó un hito en la Escuela de Salud Pública, institución que desde su fundación en 1943 fue dirigida exclusivamente por hombres, hasta recibirla como su primera Directora en 2017.

Pero fue desde su Ilegada en 2008, que dejó manifiesto su interés por el acceso equitativo a la salud, los métodos en epidemiología social y enfermedades crónicas, liderando diferentes equipos de trabajo en la Universidad de Chile, para el desarroIlo de políticas públicas en el área de la salud y el medio ambiente.

Asimismo, realizó actividades de docencia en pre y postgrado, principalmente en el Magíster en Salud Pública y el Diploma de Salud Ocupacional. Su calidad profesional la llevó a ser consultora de la Organización Mundial de la Salud y de la Organización Panamericana de Salud en temáticas relacionadas con la equidad y determinantes sociales de la salud.

Junto al Colegio Médico en 2018, participó en una propuesta titulada: "Reforma Integral al Financiamiento de la Salud", donde propuso "terminar con la segmentación y fragmentación del sistema de salud por ingreso y territorio, siguiendo un itinerario que avance paulatinamente a la financiación por impuestos generales, reduciendo la dependencia de las cotizaciones y el gasto de bolsillo". Para ello, la Dra Frenz, invitaba a proseguir a través de una discusión social amplia, por lo que probablemente, estaría orgullosa del debate impulsado, hoy, por la Universidad de Chile, en torno a los cambios necesarios para que se garantice el derecho a la salud.

Durante el último tiempo, la académica realizó investigaciones en temas de reforma de salud; derechos y garantías sociales en este mismo aspecto; atención primaria y salud urbana, liderando equipos nacionales e internacionales.

Algunas investigaciones en las que participó:

- "No decision about me, without me. Learning from international experience on approaches to community power, participation and decision-making in health" y "Learning from Promising Primary Care Models 2014", ambos liderados por Rene Loewenson, del Training and Research Support Center (TARSC) y financiados por la Charities Aid Foundation del Robert Wood Johnson Foundation.

Verónica Iglesias Directora Escuela de Salud Pública Universidad de Chile
- Investigadora principal de la Escuela de Salud Pública en el proyecto, "Salud Urbana en Latinoamérica (SALURBAL), Construyendo ciudades más saludables, equitativas y ambientalmente sostenibles: lecciones de América Latina", liderado 
por la Dra. Ana Diez Roux, decana de Dornsife School of Public Health de Drexel University (Philadelphia, Estados Unidos), financiado por Wellcome Trust, para estudiar el impacto de la urbanización y las políticas urbanas en la sostenibilidad de la salud y el medio ambiente. En este proyecto integró el comité ejecutivo y lideró junto a la Dra. Alejandra Vives (PUC), el grupo de Ambiente Social. La Dra. Diez Roux la despidió ante sus colegas del equipo SALURBAL señalando "Patricia fue una colega muy especial que siempre apoyó y estimuló la colaboración latinoamericana, e impulsó de muchas maneras el trabajo de investigación, capacitación, y diseminación que está llevando a cabo SALURBAL. Fue una gran amiga y colega de todos".

- Investigadora principal en dos proyectos FONIS: "Enfermedades no transmisibles en la población adulta de Chile: análisis longitudinal de equidad mediante las rondas de la Encuesta de Protección Social 2004 - 2012" (FONIS SA13|200138) y "Evaluación de equidad de acceso a los servicios de salud de la población chilena: desarrollo de un instrumento para la gestión territorial de salud" (FONIS SA11|2102), donde se releva su interés permanente por estudiar las inequidades en salud en nuestro país.

En su calidad humana, los cercanos a la Dra. Frenz destacan su generosidad y gran sentido del humor. Así, la recuerdan alta, con un acento norteamericano inconfundible; buena amiga; amante del arte, la música y la moda. Sus colegas, en tanto, la describen como una profesional valiente, perspicaz, inteligente y rigurosa, pero sobre todo, comprometida con el diseño e implementación de políticas que permitieran reducir, efectivamente, las desigualdades en salud.

Entre las ideas fuerza que transmitió desde que asumió la Dirección fue "que el sello de su gestión estaría orientado a potenciar los logros institucionales y tener la capacidad de afrontar nuevos desafíos, siempre desde una perspectiva de trabajo en conjunto". Así, tempranamente convocó a estudiantes, funcionarios y académicos para discutir un Plan de Desarrollo Institucional que ha sido la hoja de ruta en este período.

Su partida, el 26 de junio de 2019, fue una irreparable pérdida para esta Escuela, y para la salud pública del país. Junto con haber sido la primera directora mujer, durante su gestión tuvo la fuerza para volver a Ilenarnos de sueños, dejando entre otros desafíos el de continuar con su legado en investigación para reducir las brechas de inequidad en salud. Como Escuela de Salud Pública su mensaje nos interpela a seguir contribuyendo desde nuestro quehacer para garantizar que la salud sea un derecho.

Querida Directora, compañera y amiga, te recordaremos por siempre. 